\title{
Expression of Epstein-Barr virus-induced gene 3 in cervical cancer: Association with clinicopathological parameters and prognosis
}

\author{
YAN-MEI HOU, JUAN DONG, MING-YUAN LIU and SHAN YU \\ Department of Obstetrics, Jinan Women and Children's Health Hospital, Jinan, Shandong 250001, P.R. China
}

Received October 12, 2014; Accepted July 30, 2015

DOI: $10.3892 / \mathrm{ol} .2015 .3849$

\begin{abstract}
Epstein-Barr virus-induced gene 3 (EBI3) encodes a secretory glycoprotein, and has previously been identified as upregulated in a series of cancers. However, the clinical significance of EBI3 in cervical cancer and the potential of EBI3 as a therapeutic target for this disease have not been elucidated. In the present study, EBI3 expression was analyzed by immunohistochemistry in 90 clinicopathologically characterized cervical cancer tissue samples. The association between EBI3 expression and survival of patients with cervical cancer was also analyzed. The expression level of EBI3 in cervical cancer tissues was found to be significantly increased compared with the expression levels in the normal squamous epithelium. In addition, EBI3 expression was significantly correlated with the clinical stage and size of tumors $(\mathrm{P}<0.05)$. Furthermore, the presence of EBI3 expression was associated with a poor prognosis compared with patients without EBI3 expression. Multivariate analysis revealed that EBI3 expression was an independent predictor of overall survival (hazard ratio, 4.032; 95\% confidence interval, 1.538-7.436; $\mathrm{P}=0.035)$. To the best of our knowledge, the present results indicate for the first time that EBI3 expression is significantly associated with the progression and poor prognosis of cervical cancer. EBI3 may be a potential prognostic marker and a therapeutic target in cervical cancer.
\end{abstract}

\section{Introduction}

Cervical cancer is a malignant tumor that damages the health of women. There is a general consensus that persistent infection with high-risk human papillomavirus is the main method

Correspondence to: Dr Shan Yu, Department of Obstetrics, Jinan Women and Children's Health Hospital, 2 Jianguo Xiaojing 3rd Road, Jinan, Shandong 250001, P.R. China

E-mail: yushanjinan@126.com

Key words: Epstein-Barr virus-induced gene 3, cervical cancer, prognosis of pathogenesis for cervical cancer (1-5). Although a breakthrough has previously been achieved with regard to the etiology of this disease, the cause of the disease has not been fully elucidated. Therefore, it is of considerable importance to identify additional prognostic markers, as well as novel therapeutic methods, for cervical cancer.

In previous studies, Epstein-Barr virus (EBV)-induced gene 3 (EBI3), which was originally cloned as a gene induced in EBV-transformed B cells by the oncogene latent membrane protein 1 , demonstrated a restricted expression pattern in B-cell lymphoma (6-9). Previously, certain studies have demonstrated that EBI3 expression is also present in lung cancer and colorectal cancer tissues and plays important functions in the progression of these tumors $(10,11)$. Using tissue microarrays, Nishino et al also revealed that a high level of EBI3 expression is correlated with an unfavorable poor prognosis in lung cancer patients (10). Additional studies have confirmed that EBI3 expression is an independent prognostic factor for disease outcome in lung and colorectal cancer, as well as Burkitt lymphoma (10-12). However, the clinical significance of EBI3 in cervical cancer and the potential of EBI3 as a therapeutic target for this disease have not been clarified.

These observations prompted the current assessment of the role of EBI3 in cervical cancer. In the present study, the expression pattern of EBI3 in cervical cancer was investigated. In addition, the use of EBI3 as a potential biomarker for cervical cancer was also studied.

\section{Materials and methods}

Patients and tumor specimens. A total of 90 cervical cancer tissue samples and 6 hysteromyoma samples, obtained from cervical leiomyoma patients that had undergone surgery, were collected between 2002 and 2003 at the Department of Pathology, Jinan Women and Children's Health Hospital (Jinan, Shandong, China). The ages of the 90 patients ranged between 35 and 66 years (mean, 50.3 years). The patients consisted of 75 patients with squamous cell carcinoma and 15 patients with adenocarcinoma. The clinicopathological factors of all patients are presented in Table I. The Institute Research Medical Ethics Committee of the Jinan Women and Children's Health Hospital provided approval for the present study. 
Quantum dot (QD)-based immunohistochemical study. The QDs conjugated with streptavidin (QDs-SA) probes possessed an emission wavelength of $605 \mathrm{~nm}$. QD-immunohistochemistry (IHC) was performed using a similar procedure to conventional IHC, and the major procedures were as follows: Deparaffinization; antigen retrieval; incubation with primary antibody (polyclonal rabbit anti-human EBI3; catalog no., sc-32868; Santa Cruz Biotechnology, Inc., Dallas, TX, USA), or Tris-buffered saline in the control group; washing; incubation with the biotinylated polyclonal goat anti-rabbit IgG secondary antibody (catalog no., KIT-5905; Maxim-Bio, Fuzhou, Fujian, China); washing; administration of QDs-SA; washing; and observation (13).

IHC and immunohistochemical analysis. For antigen retrieval, $4-\mu \mathrm{m}$ tissue sections were microwaved in citrate buffer for $5 \mathrm{~min}$. The sections were incubated with the polyclonal rabbit anti-human EBI3 antibody (dilution, 1:150; catalog no., sc-32868; Santa Cruz Biotechnology, Inc.) for $40 \mathrm{~min}$ at room temperature. Antibody labeling was detected by incubating the tissue sections with biotinylated polyclonal goat anti-rabbit IgG secondary antibodies (dilution, 1:50; catalog no., KIT-5905; Maxim-Bio), followed by incubation with the avidin-biotin complex (Maxim-Bio) and diaminobenzidine (Maxim-Bio). The sections were then counterstained with hematoxylin. The expression of EBI3 was scored according to the intensity of staining, as follows: 0 , no staining; 1 , weak staining; 2 , moderate staining; and 3 , strong staining. The percentage of stained cancer cells was then used to determine the extent of staining, as follows: 0 , no stained cells; $1,<10 \%$ of cells stained; $2,10-50 \%$ of cells stained; $3,>50 \%$ of cells stained; and $4,>75 \%$ of cells stained. If the product of the intensity and extent of staining scores was $\geq 2$, the tissue was considered to be positive for the expression of EBI3.

Statistical analysis. Statistical analysis was performed using SPSS 17.0 software (SPSS, Inc., Chicago, IL, USA). The association between EBI3 expression and the clinicopathological parameters of patients with cervical cancer was evaluated using Fisher's exact test. The Cox proportional hazards regression model was performed for multivariate survival analysis. Overall survival curves were generated according to the Kaplan-Meier method. $\mathrm{P}<0.05$ was considered to indicate a statistically significant difference.

\section{Results}

Expression pattern of EBI3 in cervical cancer tissue samples. Immunohistochemical staining for the expression of EBI3 was evaluated in 90 cervical cancer tissue samples. As exhibited in Fig. 1, the expression of EBI3 was observed in 58 out of the 90 tissue samples (64.4\%). However, EBI3 expression was not detected in the normal squamous epithelium. Immunoreactivity for EBI3 was predominantly expressed in the cytoplasm of cancer cells, and not in the nuclei of cancer and stromal cells.

QD-based immunohistochemical study. Previously, QD-based immunohistochemical staining has resulted in a considerable progression in molecular imaging, particularly in studies investigating cancer $(13,14)$. In the present study, EBI3 expression was indicated by bright red QD fluorescence and was observed in the cytoplasm of cancer cells (Fig. 2); this pattern is consistent with the results of traditional immunohistochemical technology. This result confirmed the expression pattern of EBI3 in cervical cancer cells.

Association between EBI3 expression and the clinicopathological factors of patients with cervical cancer. The expression rates of EBI3 in cervical cancer tissue samples were associated with clinicopathological features are presented in Table I. In this assay, EBI3 expression was observed to be significantly associated with the clinical stage $(\mathrm{P}=0.024)$ and size $(\mathrm{P}=0.022)$ of the cervical cancer tumors. By contrast, there was no significant association between the expression of EBI3 and other clinicopathological parameters, including patient age, pathological tumor grade and presence of lymph node metastasis $(\mathrm{P}>0.05)$.

Effect of EBI3 expression on the overall survival in patients with cervical cancer. The role of EBI 3 as a predictor of disease outcome was studied in cervical cancer patients. Univariate Cox regression analysis demonstrated that the clinical stage, presence of lymph node metastasis and expression of EBI3 were significantly associated with the overall survival rate of patients with cervical cancer. As features that are observed to exert a prognostic effect in univariate analysis may covariate, the clinicopathological factors that were significantly associated with outcome in univariate analysis were further examined using multivariate analysis (Table II). The results indicated that EBI3 expression was an independent prognostic factor for poor survival in patients with cervical cancer (hazard ratio, 4.032; $95 \%$ confidence interval, 1.538-7.436; $\mathrm{P}=0.035$ ) (Table II). The clinical stage and presence of lymph node metastasis were also confirmed to be independent predictors for patient survival $(\mathrm{P}<0.05)$. In all clinicopathological parameters, the presence of lymph node metastasis was the most significant independent parameter for the prediction of prognosis $(\mathrm{P}=0.013)$.

To elucidate the prognostic role of EBI3 in cervical cancer, the overall patient survival time was estimated using Kaplan-Meier survival curves. As shown in Fig. 3, patients that expressed EBI3 demonstrated a shorter overall survival time compared with patients that without EBI3 expression $(\mathrm{P}<0.05)$ (Fig. 3).

\section{Discussion}

Previously, certain studies have revealed the presence of EBI3 overexpression in a series of tumors (8-11). EBI3 was also found to be highly expressed in patients with non-small cell lung cancer (10). Furthermore, strong EBI3 expression in lung cancer tissues has been revealed to be correlated with a poor patient prognosis (10). The expression of EBI3 has also been identified in Hodgkin's lymphoma and acute myeloid leukemia cells $(7,15)$. However, the expression pattern of EBI3 and the clinical significance of EBI3 expression in cervical cancer remains to be elucidated.

Interleukin (IL)-35 is a member of the IL family and exerts an immunosuppressive function on regulatory $\mathrm{T}$ cells (16-21). 
Table I. Association between EBI3 expression and clinical features in patients with cervical cancer.

\begin{tabular}{|c|c|c|c|c|}
\hline \multirow[b]{2}{*}{ Clinical features } & \multirow[b]{2}{*}{ Total, $\mathrm{n}$} & \multicolumn{2}{|c|}{ EBI3 expression } & \multirow[b]{2}{*}{ P-value } \\
\hline & & Present & Absent & \\
\hline Age & & & & 0.512 \\
\hline$<50$ years & 43 & 26 & 17 & \\
\hline$\geq 50$ years & 47 & 32 & 15 & \\
\hline Tumor size & & & & $0.022^{\mathrm{a}}$ \\
\hline$<4 \mathrm{~cm}$ & 59 & 33 & 26 & \\
\hline$\geq 4 \mathrm{~cm}$ & 31 & 25 & 6 & \\
\hline Pathological grade & & & & 0.120 \\
\hline G1 & 35 & 19 & 16 & \\
\hline $\mathrm{G} 2+\mathrm{G} 3$ & 55 & 39 & 16 & \\
\hline Histological type & & & & 0.547 \\
\hline Squamous carcinoma & 75 & 48 & 27 & \\
\hline Adenocarcinoma & 15 & 10 & 5 & \\
\hline Clinical stage & & & & $0.024^{\mathrm{a}}$ \\
\hline $\mathrm{I}+\mathrm{II}$ & 56 & 31 & 25 & \\
\hline III+IV & 34 & 27 & 7 & \\
\hline Lymph node metastasis & & & & 0.656 \\
\hline Absent & 54 & 36 & 18 & \\
\hline Present & 36 & 22 & 14 & \\
\hline
\end{tabular}

${ }^{\mathrm{a}} \mathrm{P}<0.05$. EBI3, Epstein-Barr virus-induced gene 3.
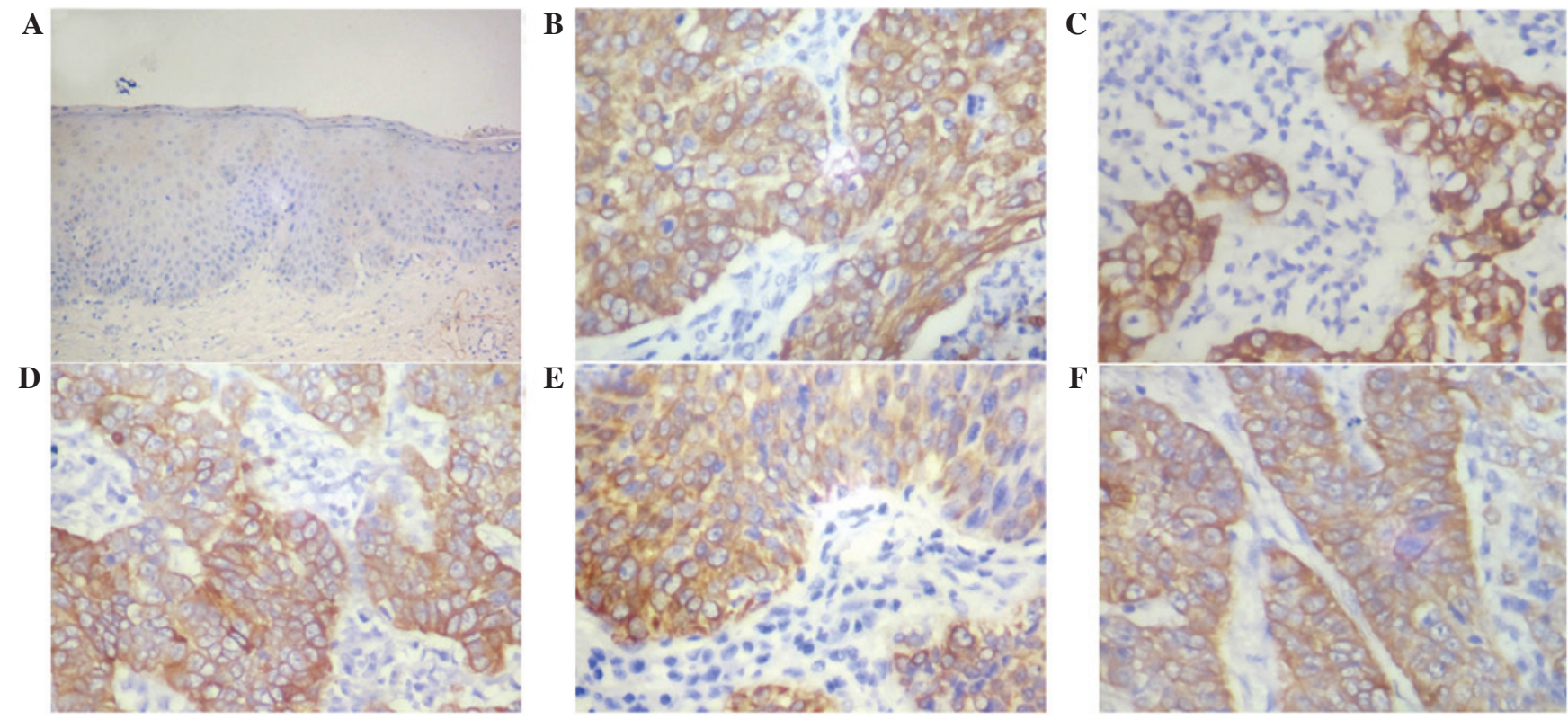

Figure 1. Immunohistochemical analysis of Epstein-Barr virus-induced gene 3 expression in (A) normal cervical squamous epithelium and (B-F) cervical cancer tissues.

Previously, a series of findings revealed that IL-35 is a vital component in the development and progression of cancers, including colorectal and pancreatic cancer $(11,22)$. As a secretory glycoprotein, EBI3 dimerizes with p35-associated subunits to form IL-35 cytokines (23). With consideration of the notable role of IL-35 in cancer, it was hypothesized that EBI3, a component of IL-35, may also participate in the tumorigenesis of cervical cancer. Long et al reported that upregulated expression of EBI3 promotes the growth of lung cancer cells, while knockdown of EBI3 inhibits the 
Table II. Univariate and multivariate analysis of overall survival in patients with cervical cancer.

\begin{tabular}{|c|c|c|c|c|c|c|}
\hline \multirow[b]{2}{*}{ Factor } & \multicolumn{3}{|c|}{ Univariate analysis } & \multicolumn{3}{|c|}{ Multivariate analysis } \\
\hline & Hazard ratio & $95 \% \mathrm{CI}$ & P-value & Hazard ratio & $95 \% \mathrm{CI}$ & P-value \\
\hline Age & 1.159 & $0.894-1.234$ & 0.487 & & & \\
\hline Tumor size & 1.652 & $0.891-3.518$ & 0.243 & & & \\
\hline Clinical stage & 5.986 & $2.102-17.734$ & 0.001 & 4.337 & $1.469-9.283$ & 0.016 \\
\hline Pathological grade & 1.731 & $0.802-3.267$ & 0.385 & & & \\
\hline Histological type & 0.902 & $0.263-2.874$ & 0.867 & & & \\
\hline Lymph node metastasis & 0.172 & $0.031-0.596$ & 0.026 & 0.176 & $0.097-0.592$ & 0.013 \\
\hline EBI3 expression & 4.867 & $2.572-16.159$ & 0.008 & 4.032 & $1.538-7.436$ & 0.035 \\
\hline
\end{tabular}

EBI3, Epstein-Barr virus-induced gene 3; CI, confidence interval.
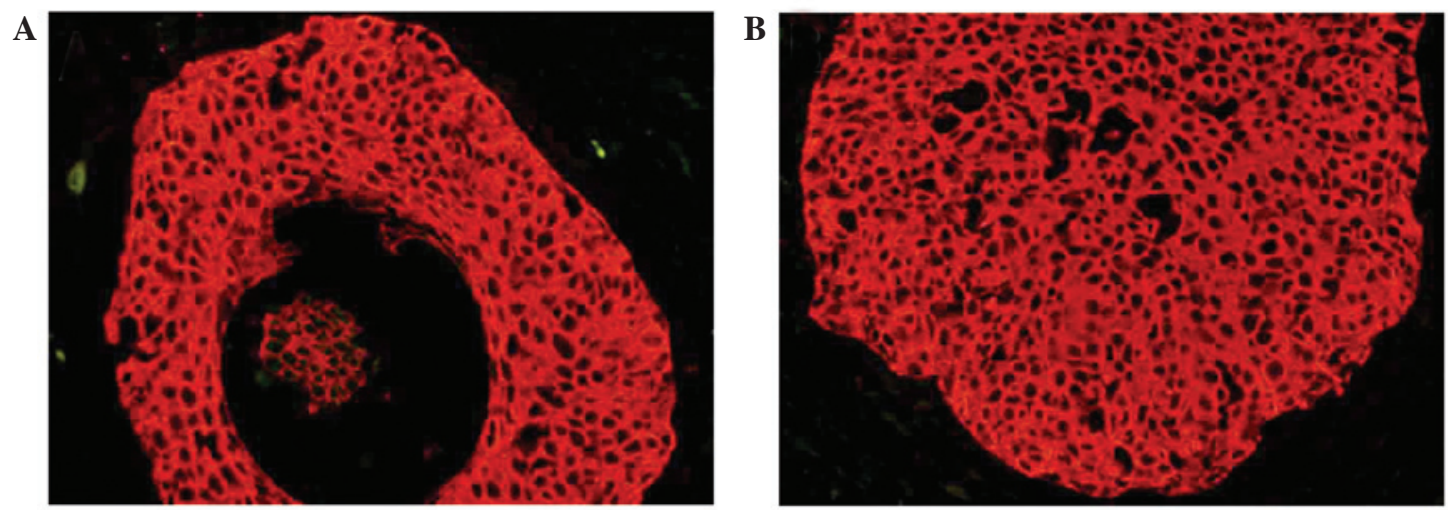

Figure 2. (A and B) Representative quantum dot-based immunohistochemical staining of Epstein-Barr virus-induced gene 3 in cervical cancer tissue specimens.

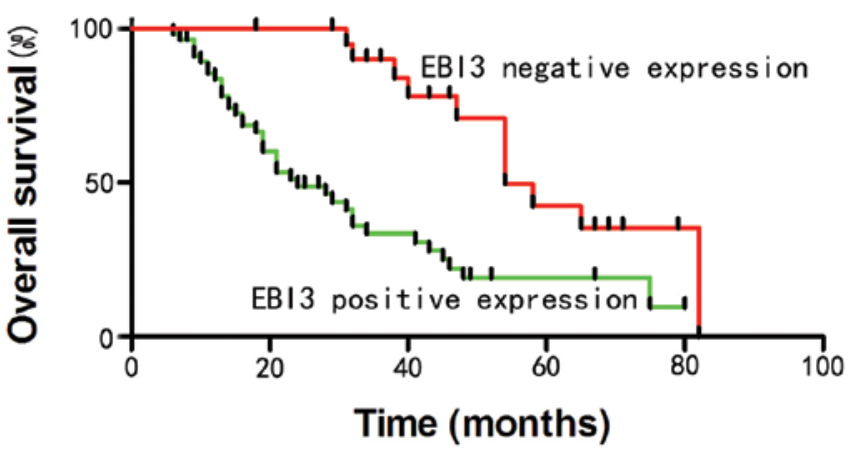

Figure 3. Kaplan-Meier analysis of the overall survival curves of patients with cervical cancer, according to the immunohistochemical staining for EBI3. The absence of EBI3 expression resulted in prolonged survival times compared with patients that demonstrated EBI3 expression. EBI3, Epstein-Barr virus-induced gene 3 .

proliferation of lung cancer cells (22). However, the precise function of EBI3 is not well understood in cervical cancer.

To the best of our knowledge, the present study is the first to report the EBI3 expression pattern in cervical cancer. In the current study, EBI3 staining was observed in $64.4 \%$ of the cervical cancer tissue specimens. In addition, EBI3 expression was confirmed to be significantly associated with the tumor size and clinical stage, as well as a poor prognosis in cervical cancer patients. The present results demonstrated that EBI3 is involved in the progression of cervical cancer. Nishino et al previously revealed that the lung cancer COS-7 cell line, which expresses exogenous EBI3, exhibited significant rapid cell growth compared with control mock cells. Furthermore, cells that stably expressed EBI3 formed larger colonies compared with the control cells, indicating the potential oncogenic effect of EBI3 in lung cancer. By contrast, knockdown of EBI3 expression by small interfering RNA significantly inhibited the growth of lung cancer cells (10). The present results suggested that EBI3 expression was associated with an increased tumor size, and also confirmed that EBI3 may be involved in the growth of cervical cancer cells. In lung cancer patients, serum EBI3 was identified as a single-tumor marker for early stage lung cancer (10). However, the present data indicated that the positive rate of EBI3 was significantly increased in advanced-stage cervical cancer tissue samples compared with the rate in early-stage cervical cancer tissues. One reason for this discrepancy between studies may be the various types of cancers investigated.

In conclusion, the present study demonstrated that EBI3 is highly expressed in cervical cancer tissues. In addition, EBI3 was identified as a prognostic biomarker for cervical cancer and it may be a possible target for the treatment of cervical cancer. 


\section{References}

1. Mikami Y: Cervical cancer. Rinsho Byori 62: 596-604, 2014 (In Japanese).

2. Mirzaie-Kashani E, Bouzari M, Talebi A and Arbabzadeh-Zavareh F: Detection of human papillomavirus in chronic cervicitis, cervical adenocarcinoma, intraepithelial neoplasia and squamus cell carcinoma. Jundishapur J Microbiol 7: e9930, 2014.

3. Petry KU: Hpv and cervical cancer. Scand J Clin Lab Invest Suppl 74: 59-62, 2014

4. Tobing MD, Sahiratmadja E, Dinda M, Hernowo BS and Susanto H: Human papillomavirus genotypes profile in cervical cancer patients at Dr. Hasan Sadikin general hospital, Bandung, Indonesia. Asian Pac J Cancer Prev 15: 5781-5785, 2014.

5. Wen Y, Pan XF, Zhao ZM, Chen F, Fu CJ, Li SQ, Zhao Y, Chang H, Xue QP and Yang CX: Knowledge of human papillomavirus (HPV) infection, cervical cancer and HPV vaccine and its correlates among medical students in Southwest China: A multi-center cross-sectional survey. Asian Pac J Cancer Prev 15: 5773-5779, 2014

6. Devergne O, Hummel M, Koeppen H, Le Beau MM, Nathanson EC, Kieff E and Birkenbach $M$ : A novel interleukin-12 p40-related protein induced by latent Epstein-Barr virus infection in B lymphocytes. J Virol 70: 1143-1153, 1996.

7. Niedobitek G, Päzolt D, Teichmann M and Devergne O: Frequent expression of the Epstein-Barr virus (EBV)-induced gene, Ebi3, an IL-12 p40-related cytokine, in hodgkin and reed-sternberg cells. J Pathol 198: 310-316, 2002.

8. Larousserie F, Bardel E, Pflanz S, Arnulf B, Lome-Maldonado C, Hermine O, Brégeaud L, Perennec M, Brousse N, Kastelein R and Devergne O: Analysis of interleukin-27 (EBI3/p28) expression in Epstein-barr virus- and human T-cell leukemia virus type 1-associated lymphomas: Heterogeneous expression of EBI3 subunit by tumoral cells. Am J Pathol 166: 1217-1228, 2005.

9. Larousserie F, Bardel E, Coulomb-L'Herminé A, Canioni D, Brousse N, Kastelein RA and Devergne O: Variable expression of Epstein-Barr virus-induced gene 3 during normal B-cell differentiation and among B-cell lymphomas. J Pathol 209: 360-368, 2006

10. Nishino R, Takano A, Oshita H, Ishikawa N, Akiyama H, Ito H, Nakayama H, Miyagi Y, Tsuchiya E, Kohno N, et al: Identification of Epstein-Barr virus-induced gene 3 as a novel serum and tissue biomarker and a therapeutic target for lung cancer. Clin Cancer Res 17: 6272-6286, 2011

11. Zeng JC, Zhang Z, Li TY, Liang YF, Wang HM, Bao JJ, Zhang JA, Wang WD, Xiang WY, Kong B, et al: Assessing the role of IL-35 in colorectal cancer progression and prognosis. Int J Clin Exp Pathol 6: 1806-1816, 2013

12. Gonin J, Larousserie F, Bastard C, Picquenot JM, Couturier J, Radford-Weiss I, Dietrich C, Brousse N, Vacher-Lavenu MC and Devergne O: Epstein-Barr virus-induced gene 3 (EBI3): A novel diagnosis marker in Burkitt lymphoma and diffuse large B-cell lymphoma. PLoS One 6: e24617, 2011.
13. Chen C, Peng J, Xia HS, Yang GF, Wu QS, Chen LD, Zeng LB, Zhang ZL, Pang DW and Li Y: Quantum dots-based immunofluorescence technology for the quantitative determination of HER2 expression in breast cancer. Biomaterials 30: 2912-2918, 2009.

14. Chen C, Xia HS, Gong YP, Peng J, Peng CW, Hu MB, Zhu XB, Pang DW, Sun SR and Li Y: The quantitative detection of total HER 2 load by quantum dots and the identification of a new subtype of breast cancer with different 5-year prognosis. Biomaterials 31: 8818-8825, 2010.

15. Poleganov MA, Bachmann M, Pfeilschifter J and Mühl H: Genome-wide analysis displays marked induction of EBI3/IL-27B in IL-18-activated AML-derived KG1 cells: Critical role of two kappaB binding sites in the human EBI3 promotor. Mol Immunol 45: 2869-2880, 2008.

16. Collison LW, Workman CJ, Kuo TT, Boyd K, Wang Y, Vignali KM, Cross R, Sehy D, Blumberg RS and Vignali DA: The inhibitory cytokine IL-35 contributes to regulatory T-cell function. Nature 450: 566-569, 2007

17. Collison LW, Pillai MR, Chaturvedi V and Vignali DA: Regulatory $\mathrm{T}$ cell suppression is potentiated by target $\mathrm{T}$ cells in a cell contact, IL-35-and IL-10-dependent manner. J Immunol 182: 6121-6128, 2009.

18. Collison LW, Chaturvedi V, Henderson AL, Giacomin PR, Guy C, Bankoti J, Finkelstein D, Forbes K, Workman CJ, Brown SA, et al: IL-35-mediated induction of a potent regulatory T cell population. Nat Immunol 11: 1093-1101, 2010.

19. Seyerl M, Kirchberger S, Majdic O, Seipelt J, Jindra C, Schrauf C and Stöckl J: Human rhinoviruses induce IL-35-producing Treg via Induction of B7-H1 (CD274) and sialoadhesin (CD169) on DC. Eur J Immunol 40: 321-329, 2010.

20. Chaturvedi V, Collison LW, Guy CS, Workman CJ and Vignali DA: Cutting edge: Human regulatory T cells require IL-35 to mediate suppression and infectious tolerance. J Immunol 186: 6661-6666, 2011.

21. Li X, Mai J, Virtue A, Yin Y, Gong R, Sha X, Gutchigian S, Frisch A, Hodge I, Jiang X, et al: IL-35 is a novel responsive anti-inflammatory cytokine-a new system of categorizing anti-inflammatory cytokines. PLoS One 7: e33628, 2012.

22. Long J, Zhang X, Wen M, Kong Q, Lv Z, An Y and Wei XQ: IL-35 over-expression increases apoptosis sensitivity and suppresses cell growth in human cancer cells. Biochem Biophys Res Commun 430: 364-369, 2013.

23. Devergne O, Birkenbach $\mathrm{M}$ and Kieff E: Epstein-Barr virus-induced gene 3 and the p35 subunit of interleukin 12 form a novel heterodimeric hematopoietin. Proc Natl Acad Sci USA 94: 12041-12046, 1997. 